\title{
TỔN THƯƠNG CƠ QUAN ĐÍCH Ở NGƯờI BỆNH ĐÁI THÁO ĐƯờNG TÍP 2 Có TĂNG HUYẾT ÁP ÁO CHOÀNG TRẮNG HOẶC TĂNG HUYẾT ÁP ẨN GIẤU
}

\author{
Nguyễn Văn Lụ̣c*, Nguyễn Thị Bích Đào**, Trần Kim Trang**
}

TÓM TẮT.

Mở đâu: THA áo choàng trắng và THA ẩn giấu khó đánh giá chính xác trên thăm khám lâm sàng thông thường. Các tổn thương cơ quan đích của chúng được ghi nhận có tỉ lệ cao, đặc biệt là trên người bệnh ĐTĐ típ 2. Mục tiêu: Xác định tỉ lệ tổn thương cơ quan đích theo hai thể THA trên. Đối tượng và phương pháp nghiên cứu: Nghiên cứu mô tá cắt ngang, 306 người bệnh tại phòng khám ngoại trú Bệnh viện Nhân Dân Gia Định TP.Hồ Chí Minh. Kết quả: Tỉ lệ phì đại thất trái ở nhóm THA ẩn giấu là 40,0\%, nhóm THA áo choàng trắng là 20,7\% và không THA là 9,4\%. Ngoài ra, tỉ lệ đạm niệu và tổn thương đáy mắt ở nhóm THA ẩn giấu cũ̃ng cao hơn so với THA áo choàng trắng và không THA. Kết luận: Việc phát hiện các thể THA này và tổn thương các cơ quan đích ở người ĐTĐ típ 2 là cần thiết, giúp phát hiện và điều trị sớm, phòng ngừa các tác động bất lợi.

Tư khóa: tổn thương cơ quan đích, THA áo choàng trắng, THA ẩn giấu, ĐTĐ típ 2

\section{SUMMARY}

TARGET ORGAN DAMAGE IN DIABETIC PATIENTS WITH WHITE COAT HYPERTENSION OR MASKED HYPERTENSION

Introduction: White-coat and masked hypertension can be undiagnosed in a clinical setting and have a high prevalence of target organ damage, especially in diabetic subjects. Objectives: To determine the prevalence of target organ damage of diabetic type 2 patients with white-coat or masked hypertension. Method: A cross-sectional study was conducted in 306 diabetic type 2 patients in outpatient department of Nhan Dan Gia Dinh hospital - HCM city. Results: The prevalence of left ventricular hypertrophy were $40.0 \%$ in masked hypertension group, $20.7 \%$ in white-coat hypertension group and $9.4 \%$ in normotensive group. Besides, proteinuria and retinopathy had a higher prevalence among masked hypertensives than white-coat hypertension and normotension. Conclusion: Early detection whitecoat or masked hypertension and their target organ damage in type 2 diabetic subjects is necessary to manage and prevent adverse events.

Keyword: target organ damage, white-coat hypertension, masked hypertension, diabetes type 2 .

*Bệnh viện đa khoa tỉnh Binh Dương

**Đại học Y dược thành phố Hồ Chí Minh

Chịu trách nhiệm chính: Nguyễn Văn Lực

Email: nguyenvanlucphoto@gmail.com

Ngày nhận bài: 21.12.2020

Ngày phản biện khoa học: 25.01.2021

Ngày duyệt bài: 8.2.2021

\section{I. ĐĂT VẤN ĐỀ}

Việc chẩn đoán và điều trị tăng huyết áp (THA) thông thường chỉ dựa vào kết quả đo huyết áp khi thăm khám lâm sàng, ghi nhận là có hoặc không THA. Với sự hỗ trợ của thiết bị đo huyết áp liên tục 24 giờ, các nhà nghiên cứu xác định còn có các thể THA khác như THA áo choàng trắng và $T H A$ ẩn giấu.

Theo ghi nhận của Hội tim mạch Quốc gia Việt Nam (2018), tỉ lệ THA ẩn giẩu và THA áo choàng trắng ngày càng gia tăng trong dân số(1). Tuy nhiên, việc chú ý đến các thể THA này chưa được các bác sĩ lưu ý trong quá trình khám bênh. Đối với đối tượng THA ẩn giấu, các đặc điểm về biến thiên huyết áp, các hiện tượng về trũng huyết áp ban đêm và tăng vọt huyết áp vào buổi sáng là những yếu tố liên quan với các biến chứng tim mạch và tổn thương các cơ quan đích.

Kể từ khi phát hiện ra các thể THA ẩn giấu và THA áo choàng trắng, nhiều nghiên cứu ghi nhận có mối liên quan với việc tổn thương các cơ quan đích. Trong đó, THA ẩn giấu có mức độ gây hại cao hơn so với THA áo choàng trắng ${ }^{(3)}$. Mức độ gây hại lên cơ quan đích của THA sẽ mạnh hơn nếu người bệnh có các bệnh lý đi kèm, đặc biệt là đái tháo đường (ĐTÐ) típ 2.

Nghiên cứu được tiến hành nhằm mục đích đánh giá tình trạng THA của người bệnh ĐTĐ típ 2, xác định các tốn thương cơ quan đích do các thể THA này gây ra, từ đó có chiến lược phát hiện và điều trị sớm, phòng ngừa các tác động bất lợi của THA đối với người bệnh ĐTĐ típ 2.

\section{II. ĐỐI TƯỢNG VÀ PHƯƠNG PHÁP NGHIÊN CỨU}

1.Thiết kế nghiên cứu: Nghiên cứu mô tả cắt ngang.

2. Đối tượng nghiên cứu: Người bệnh đênn khám ngoại trú tại Bệnh viện Nhân Dân Gia Định TP.Hồ Chí Minh, từ tháng 3/2018 đến tháng 6/2020.

Tiêu chí chọn mẫu:

- Bệnh nhân đang điều trị hay mới chẩn đoán ĐTĐ típ 2 theo tiêu chuẩn chẩn đoán của Hiệp hội ĐTĐ Hoa kỳ năm 2017.

- Bênh nhân trên 18 tuổi

- Không đang uống thuốc hạ áp.

Bênh nhân đồng ý tham gia nghiên cứu.

Tiêu chí loại trừ:

- ĐTÐ típ 1.

- ĐTÐ do thai kỳ. 
- Bệnh nhân mắc các bệnh lý cấp tính như: có sốt (trên $380 \mathrm{C}$ ), nhiễm trùng đường tiểu, đang điều trị với cimetidine; có hoạt động thể lực gắng sức trong vòng 24 giờ; đang hành kinh; nước tiểu dưới $500 \mathrm{ml} / 24$ giờ.

- Bệnh nhân có tiền căn đột quy, suy tim với EF dưới $50 \%$, suy thận mạn với nồng độ creatinine huyết thanh trên $2 \mathrm{mg} / \mathrm{dl}$ hoặc tăng huyết áp đang điều trị.

3. Đánh giá huyết áp liên tục 24 giờ. Người bệnh được đo huyết áp liên tục 24 giờ bằng máy MICROLIFE 24H WATCHBP O3, được kiểm nghiệm qua ba tiêu chuẩn quốc tế: Hiệp hội Tăng huyết áp Anh, Châu Âu và Hiệp hội Dụng cụ Y khoa. Máy đo theo phương pháp dao động mạch, nhỏ, băng từ ghi lại kết quả trong 24 giờ. Màn hình hiển thị huyết áp tâm thu, huyết áp tâm trương, tần số tim. Máy đo tự động bơm căng túi hơi và xả hơi từ từ 2-3 $m m H g$. Băng quấn: $25 \times 35 \mathrm{~cm}$. Phần mềm AccuWinPro v3: thời gian theo dõi huyết áp 24 giờ, thời gian ngày từ 6 giờ đến 22 giờ (mối 30 phút đo 1 lần) và thời gian đêm từ 22 giờ đến 6 giờ (60 phút đo 1 lần). Dựa trên các giá trị huyết áp, nghiên cứu chia làm 4 nhóm:

- HA được xem là bình thường thật sự khi: HA tại phòng khám dưới $140 / 90 \mathrm{mmHg}$ và HALT 24 giờ có: HA ban ngày dưới 135/ $85 \mathrm{mmHg}$ và HA 24 giờ dưới 130/80 mmHg.

- THA thật sự được xác định khi:

- HA tại phòng khám $\geq 140 / 90 \mathrm{mmHg}$ và

- HALT 24 giờ có: HA ban ngày $\geq 135 /$ $85 \mathrm{mmHg}$ và/ hoặc HA 24 giờ $\geq 130 / 80$ mmHg.

- THA ẩn giấu

- Huyết áp đo ở phòng khám dưới 140/ $90 \mathrm{mmHg}$ và

- HALT 24 giờ: HA ban ngày $\geq 135 / 85$ mmHg và hoặc HA 24 giờ $\geq 130 / 80$ mmHg.
- THA áo choàng trắng: được xác định trên NB không được điều trị THA khi HA đo tại phòng khám $\geq 140 / 90 \mathrm{mmHg}$ và HALT 24 giờ có $\mathrm{HA}$ ban ngày dưới $135 / 85 \mathrm{mmHg}$ và $\mathrm{HA} 24$ giờ dưới $130 / 80 \mathrm{mmHg}$

4. Phương pháp thu thập dữ liệu: lấy mẫu ngẫu nhiên hệ thống, người bệnh thỏa mãn các tiêu chí chon mẫu và tiêu chí loai trừ. Mẫu nghiên cứu được gắn huyết áp liên tục 24 giờ, nhân viên y tế hướng dẫn người bệnh tuân thủ và ghi nhận các thông tin liên quan nghiên cứu. Ghi nhận các tổn thương cơ quan đích gồm có dày thất trái, mức độ bài xuất đạm niệu và tổn thương đáy mắt.

5. Phương pháp xử lý dữ liệu. Nghiên cứu nhập liệu trên Microsoft Excel, sử dụng phần mềm Stata 14.0 để phân tích. Phép kiểm $\chi^{2}$ đánh giá mối liên quan giữa các thể THA với các biến số định tính như giới tính, hút thuốc lá, uống rượu, tiền sử gia đình,... Phép kiểm ANOVA, post-hoc Tukey's test đánh giá mối liên quan giữa các thể THA với biến số định lượng như tuổi, các đặc điểm sinh hóa; phép kiểm Kruskal-Wallis, post-hoc Dunn's test được sử dụng khi không thỏa điều kiện đánh giá bởi ANOVA. Giá trị $p<0,05$ được đánh giá là có ý nghĩa về mặt thống kê.

\section{KẾT QUẢ NGHIÊN CỨU}

Nghiên cứu ghi nhận dữ liệu trên 306 người bệnh đến khám ngoại trú tại Bệnh viện Nhân Dần Gia Định TP.Hồ Chí Minh. Các trường hợp THA thật sự ghi nhận mới chưa được điều trị là rất ít, hầu hết đều đã được điều trị trong thời gian dài. Do đó, nghiên cứu không phân tích sâu về nhóm này. Các thể THA còn lại được so sánh trong nghiên cứu bao gồm: không THA, THA áo choàng trắng và THA ẩn giấu.

Bảng 1: Đặc điểm mẫu nghiên cứu (n=306)

\begin{tabular}{|c|c|c|c|}
\hline \multirow[b]{2}{*}{ Đặc điểm mẫu nghiên cứu } & \multicolumn{3}{|c|}{ Phân loại tăng huyết áp } \\
\hline & $\begin{array}{c}\text { Không THA } \\
(n=139)\end{array}$ & $\begin{array}{c}\text { THA áo choàng trăng } \\
(n=92)\end{array}$ & $\begin{array}{l}\text { THA ấn giấu } \\
(n=75)\end{array}$ \\
\hline Tuối (năm) & $52,2 \pm 9,9$ & $51,7 \pm 8,6$ & $59,3 \pm 9,1^{*, * *}$ \\
\hline Giới tính Nam (n, \%) & $73(52,5)$ & $26(28,3)^{*}$ & $46(61,3)^{* *}$ \\
\hline BMI $\left(\mathrm{kg} / \mathrm{m}^{2}\right)$ & $23,2 \pm 2,7$ & $23,2 \pm 2,7$ & $23,3 \pm 3,2$ \\
\hline Tiền sử gia đình THA $(n, \%)$ & $46(33,1)$ & $55(59,8)^{*}$ & $55(73,3)^{*}$ \\
\hline Tiên sử gia đình ĐTĐ $(n, \%)$ & $69(49,6)$ & $71(77,2)^{*}$ & $45(60,0)^{* *}$ \\
\hline Hút thuốc lá $(\mathrm{n}, \%)$ & $33(23,7)$ & $7(7,6)^{*}$ & $30(40,0)^{*}, * *$ \\
\hline Uống rượu bia (n, \%) & $13(9,4)$ & $2(2,2)^{*}$ & $9(12,0)^{* *}$ \\
\hline Ân măn $(n, \%)$ & $52(37,4)$ & $47(51,1)^{*}$ & $46(61,3)^{*}$ \\
\hline Tập thế dục (n, \%) & $74(53,2)$ & $30(32,6)^{*}$ & $37(49,3)^{* *}$ \\
\hline
\end{tabular}

${ }^{*} \mathrm{p}<0,05$ so với nhóm không THA, **p<0,05 so với nhóm THA áo choàng trắng

Các yếu tố như nam giới, người có tiền sử gia đình THA, ĐTĐ, hút thuốc lá, uống rượu bia, ăn 
mặn và tập thể dục có khác biệt giữa THA áo choàng trắng với không THA. Ngoài ra ghi nhận có sự khác biệt có ý nghĩa thống kê về các yếu tố độ tuổi, giới tính, tiền sử gia đình ĐTĐ, hút thuốc lá, uống rượu bia và tập thể dục giữa nhóm THA áo choàng trắng và THA ẩn giấu.

Bảng 2: Chỉ sồ huyết áp theo các thể huyêt áp $(n=306)$

\begin{tabular}{|c|c|c|c|}
\hline \multirow{2}{*}{ Chỉ số huyết áp } & \multicolumn{3}{|c|}{ Phân loai tăng huyết áp } \\
\hline & Không THA $(n=139)$ & THA áo choàng tră & THA ấn giấu $(n=75)$ \\
\hline \multicolumn{4}{|c|}{ Huyết áp phòng khám $(\mathrm{mmHg})$} \\
\hline HATT & $116 \pm 9$ & $145 \pm 5^{*}$ & $132 \pm 3^{*, * *}$ \\
\hline HATTr & $71 \pm 7$ & $81 \pm 7^{*}$ & $82 \pm 4^{* * *}$ \\
\hline \multicolumn{4}{|c|}{ Huyết áp liên tục 24 giờ (mmHg) } \\
\hline HATT $-24 g$ & $112 \pm 8$ & $116 \pm 7^{*}$ & $128 \pm 4^{*}, * *$ \\
\hline HATTr $-24 g$ & $68 \pm 6$ & $69 \pm 6$ & $81 \pm 7^{*, * *}$ \\
\hline HATT ngày & $115 \pm 8$ & $119 \pm 6$ & $130 \pm 6^{*, * *}$ \\
\hline HATTr ngày & $70 \pm 7$ & $71 \pm 6$ & $83 \pm 8^{*, * *}$ \\
\hline HATT đêm & $107 \pm 10$ & $111 \pm 9^{*}$ & $124 \pm 8^{*, * *}$ \\
\hline HATTr đêm & $64 \pm 6$ & $65 \pm 7$ & $78 \pm 7^{* * *}$ \\
\hline Trũng HA $(n, \%)$ & $103(74,1)$ & $72(78,3)$ & $63(84,0)$ \\
\hline
\end{tabular}

${ }^{*} \mathrm{p}<0,05$ so với nhóm không THA, ${ }^{* *} \mathrm{p}<0,05$ so với nhóm THA áo choàng trắng

Có sự khác biệt về các chỉ số huyết áp, chủ yếu là nhóm THA ẩn giấu so với nhóm THA áo choàng trắng và không THA.

Bảng 4: Tăng huyết áp và tổn thương cơ quan đích

\begin{tabular}{|c|c|c|c|}
\hline \multirow{2}{*}{ Tổn thương cơ quan đích } & \multicolumn{3}{|c|}{ Phân loại tăng huyết áp } \\
\cline { 2 - 4 } & $\begin{array}{c}\text { Không THA } \\
(\mathbf{n = 1 3 9 )}\end{array}$ & $\begin{array}{c}\text { THA áo choàng trắng } \\
(\mathbf{n = 9 2 )}\end{array}$ & $\begin{array}{c}\text { THA ấn giấu } \\
(\mathbf{n = 7 5})\end{array}$ \\
\hline Chỉ số khối cơ thất trái $\left(\mathrm{g} / \mathrm{m}^{2}\right)$ & $95,6 \pm 15,0$ & $93,4 \pm 13,4$ & $106,2 \pm 18,4^{*}, * *$ \\
\hline Nam & $100,7 \pm 14,4$ & $98,8 \pm 16,8$ & $108,8 \pm 18,0^{*}, * *$ \\
\hline Nữ & $90,0 \pm 12,7$ & $91,3 \pm 11,2$ & $101,9 \pm 18,7^{*}, * *$ \\
\hline Phì đại thất trái $(\mathrm{n}, \%)$ & $13(9,4)$ & $19(20,7)^{*}$ & $30(40,0)^{* * * *}$ \\
\hline Đạm niệu $(\mathrm{n}, \%)$ & $2(1,4)$ & $16(17,4)^{*}$ & $27(36,0)^{* * * *}$ \\
\hline Tốn thương đáy măt $(\mathrm{n}, \%)$ & $4(2,9)$ & $2(2,2)$ & $8(10,7)^{*}, * *$ \\
\hline
\end{tabular}

${ }^{*} \mathrm{p}<0,05$ so với nhóm không THA, ${ }^{* *} \mathrm{p}<0,05$ so với nhóm THA áo choàng trắng

Khối lượng thất trái trên diện tích cơ thể, tî lệ phì đại thất trái, đạm niệu và tổn thương đáy mắt của nhóm THA ẩn giấu cao hơn so với THA áo choàng trắng và nhóm không THA.

\section{BÀN LUÂ̂N}

Việc đánh giá huyết áp và các vấn đề liên quan đến phòng ngừa, điều trị huyết áp hầu hết đều dựa vào việc đo huyết áp tại phòng khám. Tuy nhiên, bên cạnh thể THA thật sự, THA áo choàng trắng và THA ẩn giấu thường bị bỏ qua hoặc không được đánh giá chỉ với đo huyết áp thồng thường. Các nghiên cứu gần đây cho thấy rằng cả tăng huyết áp áo choàng trắng lẫn tăng huyết áp ẩn giấu đều có liên quan với sự gia tăng các biến cố về tim mạch, đặc biệt ở bệnh nhân ĐTĐ(3).

Kết quả nghiên cứu ghi nhận các yếu tố liên quan đến các thể THA cũng chính là các yếu tố nguy cơ chính của bệnh lý THA nói chung, bao gồm tuổi, giới tính tiền sử gia đình THA, ĐTĐ, các yếu tố liên quan đến thói quen, lối sống như hút thuốc lá, uống rượu bia, ăn mặn và vận động thể lực(1). Việc người bệnh ĐTẺ típ 2 có các yếu tố nguy cơ trên cân được chú ý rà soát nhiều hơn về THA.

Vấn đề tổn thương cơ quan đích có vai trò quan trọng trong tiên lượng, dự báo các nguy cơ tim mạch chung của người bệnh THA, do đó việc thăm khám đánh giá cần được tiến hành cụ thể. Sự tác động này sẽ nghiêm trọng hơn đối với người bệnh $Đ T \bigoplus$ típ 2, vì nhóm người này được cho là tồn tại nhiều yếu tố thúc đẩy việc tổn thương cơ quan đích. Việc đánh giá tổn thương gần đây được khuyến khích sử dụng là siêu âm tim và điện tâm đồ để đánh giá tổn thương thất trái và phân loại nguy cơ THA. Đánh giá tổn thương thận thông qua microalbumin cũng được chú trọng vì đây là một trong những tổn thương dễ phát hiện. Ngoài ra, yếu tố tổn thương đáy mắt cũng được quan tâm khi đánh giá tổn thương cơ quan đích gây ra bởi THA và ĐTĐ ${ }^{(1)}$.

Các nghiên cứu trên thế giới cũng ghi nhận tỉ lệ phì đại thất trái ở nhóm THA ẩn giấu là tương đồng với nhóm THA thật sự, và cao hơn các thể 
THA còn laai(4)(6). Tỉ lệ này dao động tùy thuộc vào các đắc điểm cá nhân và xã hội của đối tượng nghiên cứu, thời điểm nghiên cứu và các yếu tố tác động khác. Nghiên cứu của chúng tôi tương đồng so với các nghiên cứu trước đó khi ghi nhận tî lệ phì đại thất trái là 40,0\% ở nhóm THA ẩn giấu, cao hơn so với nhóm THA áo choàng trẳng $(20,7 \%)$ và không THA $(9,4 \%)$.

So với nghiên cứu trước đó của Nguyễn Trần Tuyết Trinh (2014), tỉ lệ phì đại thất trái ở đối tượng THA ẩn giâu có ĐiTĐ típ 2 là $15 \%{ }^{(2)}$. Có thể thấy, sự tác động của THA ẩn giấu đang ngày càng gia tăng trong thời gian gần đây và mức độ gây tổn thương cũng nhiều hơn. Việc gia tăng mức độ tổn thương là do sự tác động của THA ẩn giấu là tương đương với THA thật sự, nhưng vì không được phát hiện, người bệnh không được điêuu trị một cách đúng đắn, dẫn đến các tổn thương khồng mong muốn luôn diễn tiến âm thầm.

Các nghiên cứu cho rằng $\mathrm{HA}$ tăng dẫn đến sự tăng áp lực đến thất trái, từ đó làm thất trái phải hoạt động mạnh hơn, lâu ngày gây phì đại thất trái ${ }^{(2)(5)(7)}$. Mắc dù THA áo choàng trắng ghi nhân là tình trạng THA không bền vững và do tác động của yếu tố tâm lý. Tuy nhiên, việc gia tăng HA cũng gây tác động đáng kể khi ghi nhân nhóm này có phì đai thất trái là $20,7 \%$, cao gấp đôi so với người bệnh không THA. Việc hỗ trợ tâm lý cho người bệnh nhằm giảm thiểu THA áo choàng trắng cũng cần được lưu ý vì cũng có tác động đáng kể đến thất trái, một trong những tổn thương cơ quan đích thường gặp của THA.

THA vừa là một yếu tố nguy cơ tim mạch vừa là yếu tố tạo thuận lợi cho sự xuất hiện của đạm niệu. Bên canh đó, yếu tố về đam niệu có ý nghĩa dự báo độc lập về các tai biến tim mạch và gợi ý về tổn thương thận ${ }^{(1)}$. Nghiên cứu của chúng tôi ghi nhận tỉ lệ đạm niệu cao ở nhóm có THA so với nhóm không THA, trong đó, THA ẩn giấu có tỉ lệ đạm niệu cao hơn so với THA áo choàng trắng. Giá trị huyết áp là một yếu tố quyết định quan trọng trong đạm niệu. Khi so sánh về $H A$ trung bình, các giá trị $H A$ của THA ẩn giấu đều cao hơn so với các thể THA còn lại trong nghiên cứu. Điều này lý giải về mức độ đạm niệu của nhóm THA ẩn giấu cao hơn các nhóm còn lai.

Tổn thương đáy mắt ở nhóm THA ẩn giấu cao hơn có ý nghĩa thống kê so với THA áo choàng trắng và không THA. Đối với người bệnh ĐTĐ típ 2, biến chứng mắt là một trong những biến chứng quan trọng cần được phòng ngừa. THA là một trong những yếu tố thúc đẩy tình trạng tổn thương này, và sự ảnh hưởng sẽ gia tăng khi người bệnh cùng có 2 bệnh lý này. Kết quả nghiên cứu chứng minh việc cần phải kiểm soát và phát hiện sớm tình trạng THA của người bệnh ĐTĐ típ 2.

Giữa THA áo choàng trắng và THA ẩn giấu, THA áo choàng trắng ít được chú ý vì được cho là không phải môt tình trang THA bền vững. Trong khi đó, THA ẩn giấu lại được ghi nhận có tác động tiêu cực như THA thật sự, thậm chí còn nhiều hơn vì không được phát hiện, đánh giá đúng mức, lâu ngày dẫn đến tổn thương nghiêm trọng các cơ quan đích. Mặc dù vậy, THA áo choàng trắng cũng có những tác động tiêu cực nhất đinh đển các cơ quan đích, cao hơn so với nhóm không tăng huyết áp, nhưng thấp hơn so với nhóm THA ẩn giấu. Việc chú ý rà soát các thể HA này có ý nghĩa quan trọng trong giảm thiểu tổn thương cơ quan đích, tăng chất lượng cuộc sống của người bệnh.

\section{KẾT LUẬN}

Tỉ lệ phì đại thất trái ở nhóm THA ẩn giấu là $40,0 \%$, nhóm THA áo choàng trắng là $20,7 \%$ và không THA là $9,4 \%$. Ngoài ra, tỉ lệ đạm niệu và tổn thương đáy mắt ở nhóm THA ẩn giấu cũng cao hơn so với THA áo choàng trắng và không THA. Việc phát hiện sớm THA ẩn giấu và giảm thiểu THA áo choàng trắng có vai trò quan trọng trong giảm tổn thương cơ quan đích, đảm bảo chất lượng điêu trị và tăng chất lượng cuộc sống của người bệnh ĐTĐ típ 2.

\section{TÀI LIẸU THAM KHẢO}

1. Hội tim mạch quốc gia Viêt Nam (2018) "Khuyến cáo về chẩn đoán và điều trị tăng huyết áp 2018". tr. 9.

2. Nguyễn Trân Tuyết Trịnh (2014) "Khảo sát tình hình tăng huyết áp ẩn giâu trên bệnh nhân đái tháo đường típ 2". Tạp chí Y học Tip.Hồ Chí Minh, 18 (1), tr. 430-434.

3. Charvat J, Chlumsky J, Szabo M, Zakovicova E, Zamrazil V (2010) "The association of masked hypertension in treated type 2 diabetic patients with carotid artery IMT". Diabetes Res Clin Pract, 89 (3), pD. 239-42.

4. Marchesi C, Maresca AM, Solbiati F, Franzetti I, Laurita E, Nicolini E, Gianni M, Guasti L, Marnini P, Venco A, Grandi AM (2007) "Masked hypertension in type 2 diabetes mellitus. Relationship with left-ventricular structure and function". Am J Hvpertens, 20 (10), pD. 1079-84.

5. Na CM, Yiu SF, Choi KL, Choi CH, Ng YW, Tiu SC (2008) "Prevalence and significance of whitecoat hypertension and masked hypertension in type 2 diabetics". Hong Kong Med J, 14 (6), pp. 437-43.

6. Tadic M, Cuspidi C, Vukomanovic V, Celic V, Tasic I, Stevanovic A, Kocijancic V (2016) "Does masked hypertension impact left ventricular 
deformation?". J Am Soc Hypertens, 10 (9), pp. 694-701.

7. Tientcheu D, Avers C, Das SR, McGuire DK, de Lemos JA, Khera A, Kaplan N, Victor R, Vongpatanasin W (2015) "Target Organ
Complications and Cardiovascular Events Associated With Masked Hypertension and WhiteCoat Hypertension: Analysis From the Dallas Heart Study". Journal of the American College of Cardiology, 66 (20), pp. 2159-2169.

\section{ĐÁNH GIÁ CHẤT LƯỢNG CUỘC SỐNG Ở PHU NỮ MÃN KINH VÀ YẾU TỐ LIÊN QUAN TẠI THÀNH PHỐ CẦN THO' NĂM 2020}

\section{TÓM TẮT}

Đặt vấn đề: Mãn kinh là thời kỳ của sự rối loạn hoạt động nội tiết trong cơ thể gây ra nhiều biến đổi về thể chất và tâm thần, ảnh hưởng đến chất lượng cuôc sống của người phu nữ. Muc tiêu: (1) Đánh giá chất lượng cuộc sống ở phụ nữ mãn kinh tại thành phố Cần Thơ năm 2020. (2) Tìm hiểu một sổ yếu tố liên quan đến chất lượng cuộc sống ở phụ nữ mãn kinh tại thành phố Cần Thơ. Đối tượng và phương pháp nghiên cứu: Nghiên cứu mô tả cắt ngang 259 phu nữ mãn kinh (từ 45-60 tuổi) có hô khẩu thường trú tại thành phố Cần Thơ từ tháng 5 đến tháng 9 năm 2020. Đánh giá chất lượng cuộc sống phư nữ mãn kinh bằng bộ công cự The Women's Health Questionaire (WHQ). Kết quả: Trung bình điểm chất lượng cuộc sống của phụ nữ mãn kinh 45-60 tuổi là $75,8 \pm 9,0$ điểm. Phụ nữ mãn kinh có chất lượng cuộc sống tốt chiếm $60,6 \%$. Phân tích đa biến ghi nhận 3 yếu tố thật sự liên quan đến chất lượng cuộc sống của phụ nữ mãn kinh (45-60 tuổi), trong đó, chất lượng cuộc sống của phụ nữ mãn kinh tốt hơn ở nhóm cư trú sống ở nông thôn, không mắc bênh mãn tính và không tiếp cận thông tin chăm sóc sức khỏe mãn kinh với $p<0,05$. Kết luân: chất lượng cuôc sống ở phụ nữ mãn kinh từ $45-60$ tuổi chưa cao, hơn $1 / 3$ phụ nữ mãn kinh có chất lượng cuộc sống chưa tốt. Cần tăng cường truyên thông can thiệp nâng cao chất lượng cuộc sống đối với phu nữ mãn kinh.

Tư khóa: mãn kinh, chất lượng cuộc sống, yếu tố liên quan

\section{SUMMARY}

\section{THE QUALITY OF LIFE AND ASSOCIATED FACTORS AMONG MENOPAUSAL WOMEN IN CAN THO CITY, 2020}

Background: During menopausal period, there are a lot of fluctuation in hormone levels making various mental and physical disorders, affecting to quality of life (QOL) for women. Objectives: (1) To assess the quality of life among menopausal women in Can Tho city, 2020. (2) To define some factors

${ }^{1}$ Trường Đại học Y dược Cần Thơ

${ }^{2}$ Bênh viên Phu sản thành phố Cần Thơ

Chịu trách nhiệm chính: Nguyễn Minh Phương

Email: nmphuong@ctump.edu.vn

Ngày nhận bài: 22.12 .2020

Ngày phản biên khoa hoc: 25.01.2021

Ngày duyệt bài: 8.2 .2021

\section{Nguyễn Minh Phương ${ }^{1}$, Lê Thị Kim Định ${ }^{2}$}

associated to quality of life among menopausal women in Can Tho city. Subjects and research methods: A cross-sectional study was conducted on 259 menopausal women (from 45-60 years) who have been permanent residence in Can Tho city from May to September 2020. The Women's Health Questionaire (WHQ) was used to assess the quality of life among menopausal women. Results: The mean QOL score among menopausal women from $45-60$ years was $75,8 \pm 9,0$. The QOL with good level among menopausal women was accounted for $60,6 \%$. There were three associated factors to QOL among menopausal women, in which, QOL was better for women in rural area, without chronic desiases and not approaching menopausal health care information ( $p$ $<0,05)$. Conclusions: The quality of life among menopausal women is not high and more than one third of them poor QOL. Communication interventions of QOL should be strengthened for menopausal women.

Keywords: menopausal women, quality of life, associated factors

\section{I. ĐĂTT VẤN ĐỀ}

Mãn kinh là giai đoạn cuối cùng của kinh kỳ trong cuộc đời người phụ nữ, là một hiện tượng sinh lý tự nhiên, thường xảy ra ở phụ nữ lứa tuổi 45-55; tuổi mãn kinh trung bình phụ nữ Việt Nam là $52 \pm 3,27$ [2]. Do điều kiện sống và việc chăm sóc sức khỏe được cải thiện nên tuổi thọ trung bình của người dần đã tăng. Tuổi thọ càng cao thời kỳ mãn kinh càng kéo dài. Như vậy người phụ nữ phải trải qua một phần ba cuộc đời trong tình trạng thiếu hụt estrogen, do đó, không thể tránh khỏi những rối loạn tiền mãn kinh, mãn kinh. Đây là thời kỳ biểu hiện ngừng kinh nguyệt vĩnh viễn một cách tự nhiên do buồng trứng không còn hoạt động, nồng độ các hormon giảm thấp. Sự biển đổi này kéo theo những thay đổi về tâm sinh lý và sức khỏe người phụ nữ [1], như rối loạn về vận mạch, bệnh lý niệu sinh dục và những bệnh lý lấu dài khác (loãng xương, các bệnh về tim mạch). Các rối loạn có thể xảy ra một cách êm đềm hay phối hợp nhiều rối loạn như bốc hỏa, vã mồ hôi đêm, rổi loạn giấc ngủ, khô âm đạo, giảm ham muốn tình dục, ,...[9]. Chính các rối loạn này ảnh hưởng trực tiếp đến chất lượng cuộc sống (CLCS) cũng 